\title{
REVIEW
}

\section{Nitric oxide in primary ciliary dyskinesia}

\author{
Woolf T. Walker*, Claire L. Jackson*, Peter M. Lackie*, Claire Hogg ${ }^{\#}$ and \\ Jane S. Lucas*
}

\begin{abstract}
Nitric oxide is continually synthesised in the respiratory epithelium and is upregulated in response to infection or inflammation. Primary ciliary dyskinesia (PCD) is characterised by recurrent sinopulmonary infections due to impaired mucociliary clearance. Despite chronic infections, nasal nitric oxide in such patients is markedly reduced and is used as a screening test for this condition. These low levels were first described $>15$ yrs ago but the underlying mechanisms have yet to be fully elucidated. We review epithelial nitric oxide synthesis, release and measurement in the upper airways with particular reference to PCD. The key hypotheses that have been proposed to explain the low nitric oxide levels in this condition are explored and the potential benefits of augmenting airway nitric oxide levels are considered. Further work in these patients clarifying both whether the respiratory epithelium is able to biosynthesise normal levels of nitric oxide and the role played by abnormalities in the anatomy of the paranasal sinuses is essential. While nitric oxide augmentation is unlikely to be beneficial in common PCD phenotypes, it has potential in the treatment of secondary dyskinesias and may also improve treatment of bacterial infections, particularly where biofilms are implicated.
\end{abstract}

KEYWORDS: Nasal nitric oxide, nitric oxide augmentation, nitric oxide synthase

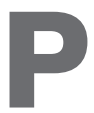

rimary ciliary dyskinesia $(\mathrm{PCD})$ is a rare autosomal recessive disorder, with considerable heterogenicity, characterised by a spectrum of corresponding defects in ciliary ultrastructure and/or ciliary function [1]. The impaired ciliary function impedes mucociliary clearance, which predisposes the patient to recurrent sinopulmonary infection [2]. Nitric oxide is a highly reactive gaseous molecule with numerous signalling roles within the airways. It is produced throughout the airways but is particularly abundant in the nasal sinuses [3]. Nitric oxide biosynthesis is typically upregulated during infection, via increased inducible nitric oxide synthase (iNOS) transcription and activity [4]. Despite recurrent respiratory infection, nasal concentrations of nitric oxide are markedly reduced in the vast majority of PCD patients, compared with those without the disorder. Indeed, nasal NO is now widely used as a screening test for PCD [5, 6]. Exhaled nitric oxide fraction $(\mathrm{FeNO})$ from the lower airway is also low in PCD but is less specific at differentiating between PCD and healthy controls [3, 7, 8]. While the association between low nasal nitric oxide and PCD has been recognised for $>15$ yrs, the underlying mechanisms causing this phenomenon remain unclear.
Here, we review studies of nitric oxide in the airway, focusing on epithelial-derived nitric oxide and the low levels found in PCD patients. We explore key hypotheses proposed to explain the lower nitric oxide and consider whether augmentation of nitric oxide would benefit these patients.

\section{THE BIOSYNTHESIS AND ROLE OF NITRIC OXIDE IN THE AIRWAY}

Nitric oxide is an intra- and intercellular signalling molecule involved in diverse physiological and pathophysiological processes [9], such as vascular homeostasis, immune cell activity and tumour progression [10]. Nitric oxide has a short half-life and diffuses rapidly from its point of synthesis, interacting intracellularly as well as crossing the plasma membrane and leaving the cell, where it can act extracellularly [11, 12]. Nitric oxide is synthesised via the oxidation of the amino acid L-arginine to L-citrulline, catalysed by three stereospecific isoenzymes in the presence of nicotinamide adenine dinucleotide phosphate, oxygen and other cofactors (fig. 1). The isoenzymes neuronal nitric oxide synthase (nNOS) and endothelial NOS (eNOS) are expressed constitutively and require calmodulin binding and calcium activity to produce femtomole or picomole concentrations of nitric oxide [13]. In contrast, iNOS is permanently
AFFILIATIONS

*Primary Ciliary Dyskinesia Centre, NIHR Respiratory Biomedical Research Unit, Division of Infection Inflammation and Immunity, Faculty of Medicine, University of Southampton, Southampton, and \#The Royal Brompton Hospital, Sydney Street, London, UK.

CORRESPONDENCE

J.S. Lucas

Primary Ciliary Dyskinesia Diagnostic and Research Team (MP 803) NIHR Respiratory Biomedical Research Unit

Southampton University Hospitals NHS Trust

Tremona Road

Southampton

S016 6YD

UK

E-mail: jlucas1@soton.ac.uk

Received:

Oct 112011

Accepted after revision:

Feb 082012

First published online:

March 092012

European Respiratory Journa

Print ISSN 0903-1936

Online ISSN 1399-3003 


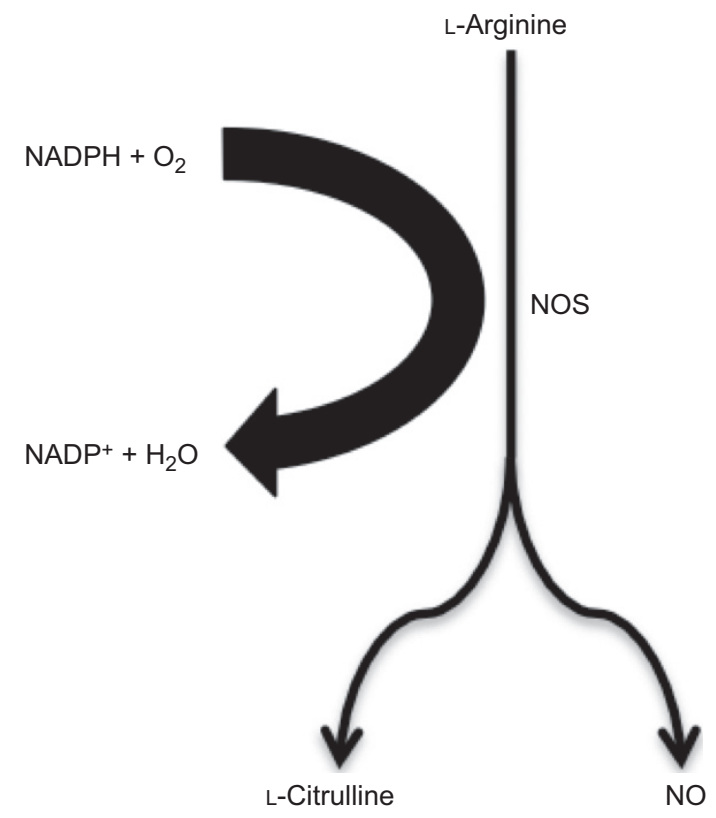

FIGURE 1. Schematic diagram to demonstrate nitric oxide biosynthesis by the conversion of L-arginine (nitric oxide synthase (NOS) substrate) to L-citrulline via NOS isoenzymes. During this process, the reduced form of nicotinamide adenine dinucleotide phosphate (NADPH), is oxidised in the presence of oxygen to form nicotinamide adenine dinucleotide phosphate $\left(\mathrm{NADP}^{+}\right)$and water. Other cofactors are also required for nitric oxide biosynthesis (not shown)

bound to calmodulin and is therefore independent of calcium activity. It may be transcriptionally induced by a number of cytokines, including interleukin- $1 \beta$, tumour necrosis factor- $\alpha$ and interferon- $\gamma[14]$, to produce nanomole concentrations of nitric oxide [4, 13]. The expression of iNOS may also be constitutive in airway epithelium [14]. NOS isoenzyme gene expression and protein localisation have been demonstrated in the airway (table 1).

Within the airway, nitric oxide is produced by numerous cell types, including epithelial cells, endothelial cells, fibroblasts, activated macrophages, nerve cells, and airway and vascular smooth muscle cells. It has diverse roles as a modulator of ciliary function, neurotransmission, bronchodilatation, vasodilatation, platelet aggregation and immune function [13]. With regard to ciliary function, in vitro studies of animal and human airway ciliated epithelium suggest that the induction of NOS and nitric oxide production increase ciliary beat frequency [20-26]. During oxidative stress conditions, the production of nitric oxide and reactive nitrogen species amplify inflammatory responses and, hence, may modulate chronic airway inflammatory disease [13]. Additionally, the production of nitric oxide within the airway is protective against infection, and has bacteriostatic and bactericidal activity; sodium nitrite can kill Pseudomonas aeruginosa, Staphylococcus aureus and Burkholderia cepacia [27]. It can also modulate biofilm formation [28], and cause biofilm dispersal, making the bacteria more susceptible to antimicrobial treatment [29].

\section{PRIMARY CILIARY DYSKINESIA}

PCD is a heterogeneous disorder, usually inherited as an autosomal recessive trait [6], causing a range of ciliary ultrastructural and functional defects, and resultant ciliary dyskinesia [30]. The prevalence of PCD is estimated to be 1 in 15,000-30,000 live births $[6,31,32]$. PCD is characterised by chronic upper and lower airway infection, and is associated with situs inversus and male infertility due to homology between respiratory cilia, embryonic nodal cilia and sperm.

The motile ciliary axoneme is formed in a "9+2" arrangement where nine peripheral microtubule doublets surround a central pair of single microtubules [33]. Over 250 other proteins maintain this structure, including radial spokes and nexin links. The inner and outer arms of the axoneme generate the force required for ciliary beating and are formed by dynein complexes, acting as mechanochemical ATPases [34]. Radial spokes structurally coordinate the ciliary beat pattern (CBP); hence, mutations affecting dynein arms or radial spokes render ciliary movement ineffective and dyskinetic [35]. Development of a genetic diagnosis for PCD has remained problematic due to the heterogenicity of the disease and, in some cases, candidate genes having large exomes. To date, there are 11 published PCD-causing gene mutations, which account for approximately one-third of PCD cases [36, 37], and genetic diagnostic techniques are being developed $[6,36]$.

\section{DIAGNOSIS}

Diagnosis of PCD can be confirmed by analysis of ciliated bronchial or nasal epithelia. There is no "gold standard" test that will diagnose all PCD phenotypes, and hence a diagnostic workup requires the rigorous assessment of $\mathrm{CBF}$ and ciliary beat pattern (CBP) by high-resolution, high-speed video microscopy and transmission electron microscopy of ciliary ultrastructure, as recommended by the European Respiratory Society Task Force consensus statement [6]. Assessment of CBP requires a high degree of experience and skill, but considering $\mathrm{CBF}$ in isolation risks misdiagnosing PCD. There is also an increasing literature on a population of atypical patients with PCD and normal ciliary ultrastructure, associated with mutations in

TABLE 1 Expression and protein localisation in the human airway of the nitric oxide synthase (NOS) isoenzymes

\begin{tabular}{|c|c|c|c|c|c|}
\hline NOS isoenzyme & Protein & Gene & Chromosome & Localisation & Reference \\
\hline Neuronal & nNOS & NOS1 & 12 & Airway neuronal cells & [15] \\
\hline \multirow[t]{2}{*}{ Inducible } & iNOS & NOS2 & 17 & Airway epithelial cells & [16] \\
\hline & & & & Paranasal epithelial cells & [18] \\
\hline Endothelial & eNOS & NOS3 & 7 & Airway epithelial and endothelial cells & [19] \\
\hline
\end{tabular}


dynein axonemal heavy chain [11], that would be missed in centres where diagnosis depends on electron microscopy without access to high-speed video microscopy [38-40]. For difficult diagnostic cases, the re-differentiation of basal epithelial cells at an air-liquid interface in cell culture allows for reassessment of ciliary function and ultrastructure that may differentiate primary from secondary dyskinesia [6, 41, 42].

\section{SCREENING: THE ROLE OF NASAL NITRIC OXIDE}

Only a small percentage of patients presenting with chronic upper and lower respiratory tract infections have PCD. Diagnostic investigation of PCD, outlined above, requires specialist skills, and is time consuming, costly and only available in a small number of specialist centres. A reliable screening test is therefore desirable [41]. For many years, the saccharin test was used, but it is difficult to perform and is unreliable in children $[6,43]$.

Nitric oxide detection in human exhaled breath was first described in 1991 [44]. Studies suggest that the majority of nitric oxide originates from the paranasal sinuses, with lower concentrations found in exhaled breath [18, 45]. Paranasal sinus biopsies taken from healthy controls demonstrated that iNOS isoenzyme expression was most abundant in in situ hybridisation and immunohistochemistry experiments, and notably more so than seen in matched nasal biopsies, suggesting iNOS as the predominant isoenzyme involved in nitric oxide biosynthesis within the paranasal sinuses $[18,46]$.

PCD patients have low nasal nitric oxide and FeNO compared with healthy controls (table 2) [3, 7, 8]. Nasal nitric oxide is sufficiently low in PCD to be used as a screening test for the condition $[3,7,47,48,52,54]$. One group reported a specificity of $88 \%$, a sensitivity of $100 \%$ and a positive predictive value of $89 \%$ for correctly diagnosing PCD when using a nasal nitric oxide cut-off level of $<105 \mathrm{ppb}$ [48]. While initially undertaken as a research tool, nasal nitric oxide was quickly introduced as part of the clinical diagnostic pathway in many larger European PCD centres. It has been included in the British guidelines since
2007 [5] and European consensus guidelines since 2009 [6]. Nasal nitric oxide measurement is not yet approved for clinical use in the USA where only centres with major research programmes in PCD are routinely using it. The measurement is extremely helpful in guiding the diagnostic pathway, but major drawbacks are the cost of equipment and consumables. It is also important to note that there is no widely agreed cut-off level used for the screening of PCD as levels vary significantly with age, due to the development of the paranasal sinuses over the first decade of life, and, to a lesser extent, with the device used to perform the measurement $[18,55]$. Nasal nitric oxide has also been found to be useful in atypical phenotypes where normal ciliary ultrastructure makes diagnosis difficult $[38,54]$. While the best validated technique for the measurement of nasal nitric oxide is performed by nasal aspiration during breath holding [56], there is recent literature on levels recorded in PCD patients during both humming and tidal breathing. Tidal measurements allow levels to be measured in children as young as 6 months of age, although there is limited experience in this age younger age group $[55,57]$.

Contrary to the majority of published data $[3,7,47,48,52,54]$, two groups $[53,58]$ have recently reported normal and raised levels of nasal nitric oxide in patients with PCD. A study of PCD-positive patients, confirmed by live ciliary function analysis and scrutiny of ciliary axonemal ultrastructure [6], reported five patients with nasal nitric oxide within or above the normal range [53]. A further study demonstrated that $24 \%$ of patients at an Italian PCD clinic $(n=41)$ had nasal nitric oxide of $>250 \mathrm{ppb}$, although the diagnostic evidence for PCD in these patients is unclear [58]. These studies highlight that patients with a history strongly suggestive of PCD should not be excluded from further diagnostic evaluation on the basis of nasal nitric oxide.

The value of using nasal nitric oxide as a screening tool for PCD is clear, but there are a number of other conditions in which reduced nasal nitric oxide levels occur, although usually

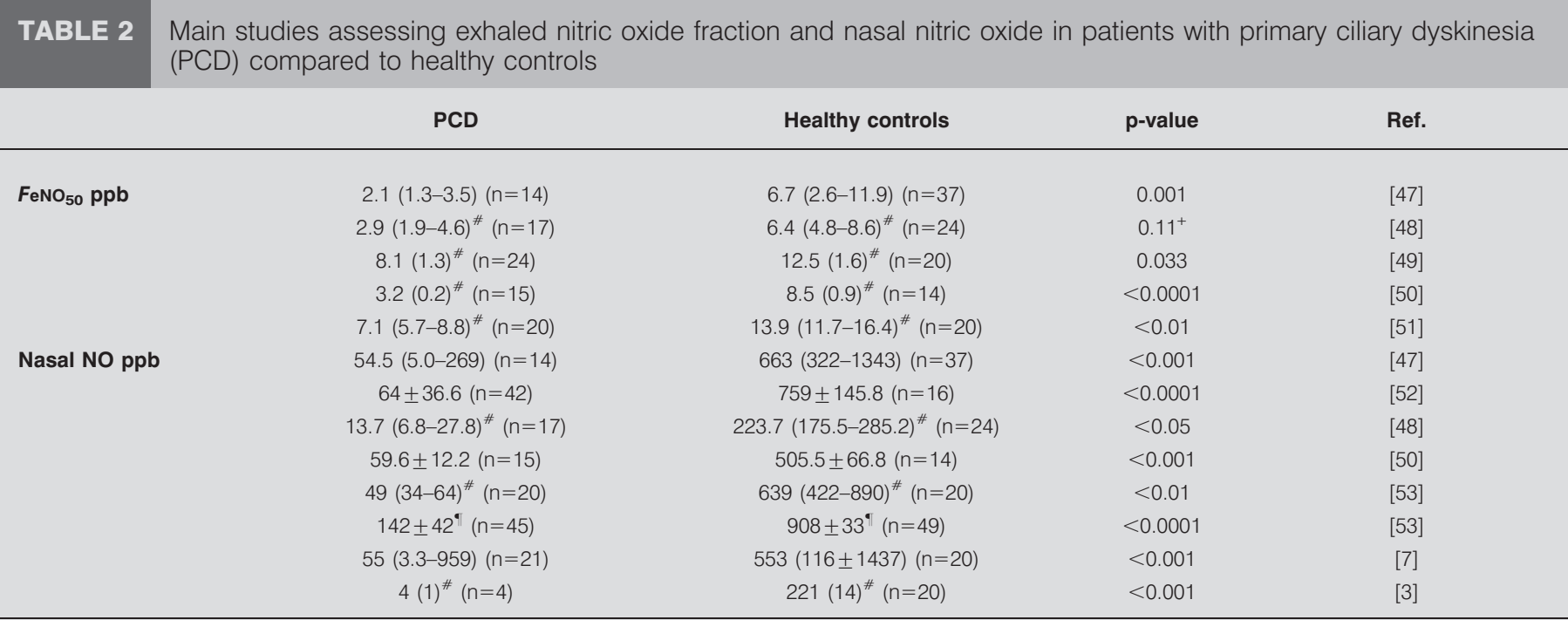

Data are presented as median (range) or mean $\pm \mathrm{SD}$, unless otherwise stated. $\mathrm{FeNO}_{50}$ : exhaled nitric oxide measured at a set exhalation flow rate of $50 \mathrm{~mL} \cdot \mathrm{s}^{-1} .{ }^{\#}:$ mean $(95 \% \mathrm{Cl}) ;{ }^{\bullet}:$ mean $\pm \mathrm{SE} ;{ }^{+}$: nonsignificant. 
not as low as in PCD, including cystic fibrosis [59], diffuse panbronchiolitis [60], nasal polyps [61] and chronic sinusitis [62]. It is also reduced in smokers [63]. The lack of specificity requires robust diagnostic evaluation to confirm PCD in patients with low nasal nitric oxide.

\section{MEASUREMENT OF ALVEOLAR AND BRONCHIAL NITRIC OXIDE IN HEALTH AND IN PCD}

Exhaled lower airway nitric oxide as measured by $F$ eNO is typically sampled at a set exhalation flow rate of $50 \mathrm{~mL} \cdot \mathrm{s}^{-1}$, denoted as $\mathrm{FeNO}_{50}$ [56]. Several two-compartment mathematical models have been described, allowing estimates of alveolar nitric oxide $(\mathrm{Calv}, \mathrm{NO})$ and conducting airway nitric oxide $\left(J^{\prime}\right.$ aw,NO) $[64,65]$. The two-compartment model has been used to investigate whether low nitric oxide is confined to the upper airway in PCD, or whether it is low throughout upper and lower airways. Three published studies that have used the multipleflow technique to estimate $J^{\prime}$ aw, NO and $\mathrm{Calv}, \mathrm{NO}$ in PCD patients have conflicting findings $[49,51,66]$. All found $J$ 'aw,NO was reduced in PCD compared with controls but only one [66] found low Calv,NO. While further work is needed to consider this discrepancy, the model might suggest that the lower $\mathrm{FeNO}_{50}$ seen in PCD compared to controls is principally due to a decreased bronchial biosynthesis of nitric oxide.

\section{WHY ARE NITRIC OXIDE LEVELS REDUCED IN PCD?}

Several hypotheses have been put forward at both a cellular and anatomical level for the low airway nitric oxide in PCD; some extrapolated from the finding of reduced nitric oxide levels seen in cystic fibrosis [67-70]. At the epithelial level, it has been suggested that there is reduced biosynthesis of $\mathrm{NO}[8,50,69]$ or increased breakdown, either within the cell, in a viscous mucus layer $[67,68]$ or by denitrifying bacteria [50]. At the anatomical level, it has been suggested that nitric oxide is sequestered in the upper respiratory tract within blocked paranasal sinuses or, alternatively, nasal nitric oxide biosynthesis or nitric oxide storage capacity is limited due to agenesis of the sinuses (fig. 2) [58, 71].

We review below four broad hypotheses that have been proposed to explain the low nitric oxide levels found in patients with PCD.

\section{HYPOTHESIS 1: INCREASED BREAKDOWN OF NITRIC OXIDE TO METABOLITES}

As nitric oxide is highly reactive, it is rapidly broken down from the breath exhalate by its reaction with, among others, oxygen, superoxides and cysteine thiols, producing reactive nitrogen species, including the potent oxidants peroxynitrite and nitrogen dioxide, and S-nitrosothiols [72-75].

The low nitric oxide levels seen in PCD may be associated with increased consumption of nitric oxide by superoxide anions to form reactive nitrogen species, which has been suggested as the cause of low nitric oxide in adult respiratory distress syndrome [76]. A study of 23 PCD patients and 11 healthy volunteers seemed to support this, demonstrating increased concentrations of the oxidative stress marker 8-isoprostane (8-IP) in the PCD group. However, there were a number of PCD patients with apparently normal 8-IP levels, which is inconsistent with oxidative stress associated rapid breakdown of nitric oxide in these patients [77]. CsOMA et al. [50] demonstrated no difference in the mean concentrations of three nitric oxide metabolites (nitrite,

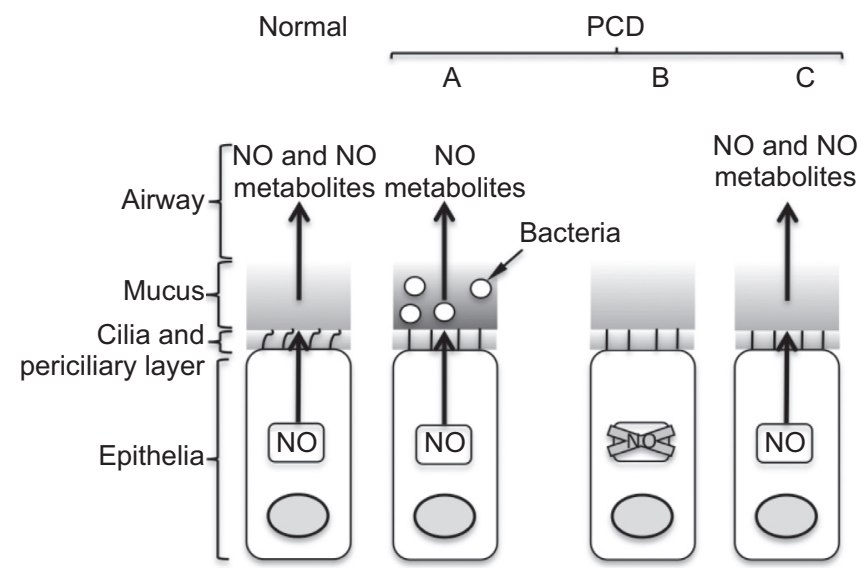

FIGURE 2. Schematic diagram to represent normal nitric oxide metabolism and release from the epithelium of healthy subjects, and hypotheses for the potential causes of low nasal nitric oxide concentrations in primary ciliary dyskinesia (PCD), based on events at the epithelium. A: increased breakdown of highly reactive nitric oxide to nitric oxide metabolites (nitrite and nitrates), either within the epithelial cell, within extra viscous sputum or by denitrifying bacteria within the mucus; hence, nitric oxide metabolites are predominantly released into the airway (hypothesis 1). B: absence of, or reduced, nitric oxide biosynthesis within the epithelial cell (hypothesis 2). C: normal nitric oxide biosynthesis within the epithelial cell; however, obstruction to the osteomeatal complex inhibits nitric oxide release from the paranasal sinuses into the nasal passage (hypothesis 3). Alternatively, hypoplasia or agenesis of the paranasal sinuses reduces nitric oxide production and storage capacity; hence, low measurable nasal nitric oxide levels are seen (hypothesis 4)

nitrite/nitrate or S-nitrosothiol) in the exhaled breath condensates of 15 PCD patients with markedly decreased nasal nitric oxide levels (table 2), compared with 14 healthy controls, suggesting that nitric oxide biosynthesis does occur in the PCD airway. Given the variability in levels of oxidative stress seen in PCD patients, it seems unlikely that this alone is responsible for the consistently low nitric oxide detection in PCD; however, further experimental work is required.

Nitric oxide is trapped and broken down in viscous sputum Impaired mucociliary clearance in PCD causes mucus accumulation in the airways, potentially trapping nitric oxide at the periciliary level or in the mucus itself, where it is then broken down into nitric oxide metabolites. In cystic fibrosis patients, it has been suggested that the viscous mucus may trap the highly reactive nitric oxide, preventing it from being exhaled freely $[67,68]$. Viscous mucus is a particular issue for cystic fibrosis patients but similar biophysical properties have been identified in sputum of patients with PCD [78]. The significance of this potential mechanism requires further evaluation.

\section{Consumption of nitric oxide by denitrifying bacteria}

Increased breakdown of airway nitric oxide by bacterial nitric oxide reductase may contribute to low FeNO [79]. There is evidence in cystic fibrosis that chronic colonisation of the airway with denitrifying organisms lowers FeNO and that antibiotic treatment for exacerbations increases nitric oxide concentrations [70]. PCD patients similarly suffer from recurrent infection and, to some degree, colonisation, but to our knowledge, the effect of antibiotic treatment on FeNO has not been assessed. However, 
denitrifying bacteria seem unlikely to be the cause of the low nitric oxide concentrations seen as cystic fibrosis patients are more chronically colonised with bacteria than patients with PCD but have significantly higher nasal nitric oxide concentrations.

\section{HYPOTHESIS 2: REDUCED BIOSYNTHESIS OF NITRIC OXIDE}

Nitric oxide synthesis occurs in patients with PCD [50]; however, a number of reasons why synthesis may be reduced in PCD epithelia have been postulated. These include an absence or decreased expression of NOS isoenzymes, a reduction in NOS isoenzyme output directly related to loss of ciliary function [8] or limitations in the availability of the NOS substrate L-arginine, either due to its reduced availability or increased metabolism $[69,80-82]$.

\section{Decreased expression of NOS isoenzymes}

It has been suggested that iNOS is the main contributor to FeNO, when looking at healthy, asthmatic and atopic children [83]. It has also been reported that patients with cystic fibrosis have reduced or absent iNOS expression in the airway epithelia [79, 84, 85]. A recent study comparing NOS2 and NOS3 mRNA expression (the genes for iNOS and eNOS, respectively) in the nasal mucosa of patients with PCD and secondary ciliary dyskinesia (SCD) found that there was no difference in NOS3 expression but lower levels of NOS2 expression in the PCD group. There was, however, significant overlap between the two groups, making these results difficult to interpret. [82]. Since PCD is a polygenic disorder, its genetic linkage to NOS gene polymorphisms is highly unlikely. Furthermore, "next-generation sequencing" of exomes, targeted to identify PCD causing genetic mutations, to date, has not identified the NOS genes (NOS1, NOS2 and NOS3) as candidate genes for PCD [36].

\section{Loss of NOS activity via mechanochemical uncoupling in $P C D$}

NARANG et al. [8] proposed that normal NOS activity requires ciliary function via a mechanochemical coupling to dynein ATPases, which would be uncoupled in patients with PCD. This hypothesis was based on observations from patients with Duchenne muscular dystrophy (DMD) where mutations in the dystrophin gene result in an uncoupling of nNOS from the contractile apparatus, leading to the loss of contractile function seen in DMD, causing low serum nitric oxide [86-88]. While further work is required to elucidate the mechanism regulating NOS activity, an uncoupling of NOS from dynein ATPase seems unlikely as PCD phenotypes with hyper-frequent or motile dyskinetic cilia have low nitric oxide similar to patients with static cilia.

\section{Limitations to availability of the NOS substrate L-arginine}

Arginase competes with NOS isoenzymes for their common substrate L-arginine. It has been suggested in cystic fibrosis that high levels of arginase may be present and compete with NOS isoenzymes for L-arginine, hence leading to reduced nitric oxide biosynthesis [69]. In cystic fibrosis, high levels of arginase activity are seen in sputum even after 14 days of intravenous antibiotics, which significantly lowers arginase activity when compared with induced sputum from healthy control subjects $(p=0.0001)$ [69]. While this has not been directly assessed in PCD patients, there have been pilot studies that demonstrate increased nasal and exhaled nitric oxide levels in PCD patients following administration of both intravenous and nebulised L-arginine, as discussed further below $[82,89]$. Further work is needed to clarify the availability of this NOS substrate in PCD epithelial cells.

\section{HYPOTHESIS 3: NITRIC OXIDE IS TRAPPED IN THE OBSTRUCTED PARANASAL SINUSES}

In health, the predominant source of exhaled nitric oxide is the upper airway [45]. Evidence from studies using manoeuvres such as humming suggest nitric oxide is sequestered within the nasal cavities [71, 90,91]. The oscillation generated by the humming is thought to increase gas exchange across the osteomeatal complex [90, 92]. During tidal breathing, it can take up to $30 \mathrm{~min}$ to completely clear sinus gases into the nasal cavity, but with humming, this occurs in one exhalation [93, 94]. In healthy volunteers, humming leads to a 15 -fold peak in nasal nitric oxide, compared with quiet exhalation [90]. This humming peak is absent in patients with chronic sinusitis and those with cystic fibrosis $[91,95]$. There is evidence, in both these conditions, to suggest this is secondary to decreased expression of iNOS, leading to decreased nitric oxide biosynthesis [79, 84, 85, 96]. Patients with PCD suffer from chronic sinusitis and, in a small study, the absence of a nasal nitric oxide humming peak has been demonstrated in PCD compared with healthy controls [71]. In this study, 13 of the 14 PCD patients underwent a computed tomography scan of the paranasal sinuses and no differences were seen in nasal nitric oxide humming peaks between those who had complete opacification of the paranasal sinuses and those with only partial opacification with patent osteomeatal complexes; however, the numbers were small [71].

A recent observational study reported five patients with PCD with normal nasal nitric oxide levels [53]. Notably, none of these five patients suffered from chronic sinusitis [53], supporting the hypothesis that a patent osteomeatal complex permits normal nasal nitric oxide levels in PCD. However, in the authors' patient population, some had PCD without sinusitis but very low nasal nitric oxide and there are very few reported cases of PCD patients with normal nasal nitric oxide levels, raising the possibility that these five patients may have an unusual phenotype or have been incorrectly diagnosed with PCD.

So, while it has been demonstrated that humming does not increase nasal nitric oxide in PCD patients, it remains unclear whether this is a consequence of the underlying inability of the airway epithelia to produce nitric oxide or that the manoeuvres did not overcome the obstruction to the osteomeatal complex.

\section{HYPOTHESIS 4: REDUCED PRODUCTION AND STORAGE CAPACITY OF NITRIC OXIDE IN THE PARANASAL SINUSES}

Aplastic or hypoplastic nasal sinuses can occur in PCD and would lead to both absent or reduced epithelial production and storage capacity of NO in the paranasal sinus, respectively. This might explain, particularly given the importance of the paranasal sinuses in nitric oxide production [45], why nasal nitric oxide concentrations are low and do not vary significantly with manoeuvres that improve sinus ventilation $[58,71$, 97]. In a recent study, computed tomography scans of the paranasal sinuses at the time of diagnostic investigation for PCD demonstrated that frontal and/or sphenoidal sinuses were either aplastic or hypoplastic in $30(73 \%)$ out of 41 PCD 


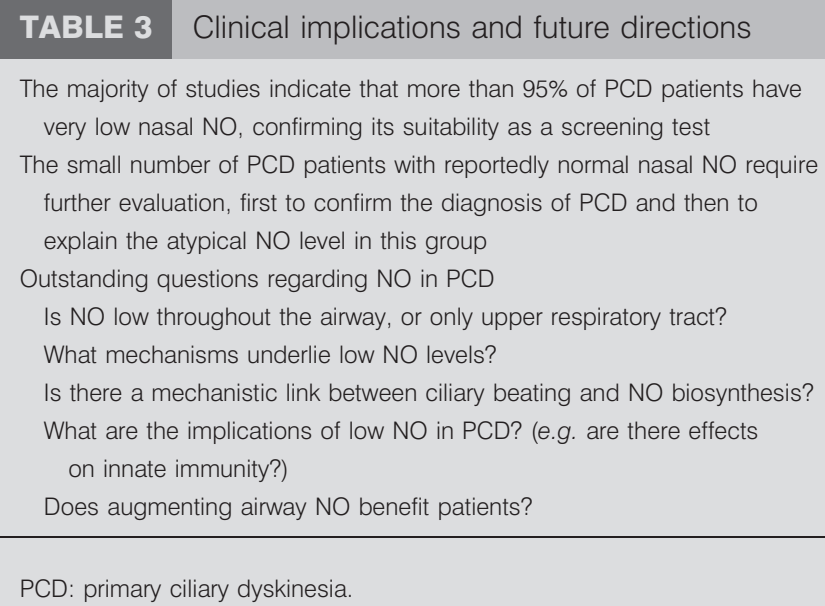

patients, compared to only $38 \%$ of those with SCD [58]. There was a significant inverse correlation between the score for aplasia/hypoplasia of each paranasal sinus and nasal nitric oxide values in PCD $(r=-0.432, p=0.008)$ but not in SCD $(r=-0.271, p=0.07)$ [58], supporting the hypothesis that smaller sinuses are associated with lower nasal nitric oxide levels. However, unusually, 24\% of this PCD study population had normal nasal nitric oxide; if these patients were excluded, no correlation between aplasia/hypoplasia score and nasal nitric oxide level would have been seen. There is again the possibility that these "outliers" with normal nitric oxide may have an unusual PCD phenotype or have been incorrectly diagnosed.

Further evidence in support of this hypothesis is that the paranasal sinuses develop over the first 10 yrs of life and nasal nitric oxide levels are seen to increase with age over this time period [18]. It is also noteworthy that most conditions associated with lower nasal nitric oxide levels involve disease of the paranasal sinuses, cystic fibrosis [59, 98], nasal polyps [61], chronic sinusitis [62] and PCD, which may lead to either obstruction of the osteomeatal complex or reduced storage capacity of the paranasal sinuses, or a combination of both.

\section{THE VALUE OF AUGMENTATION OF NITRIC OXIDE LEVELS IN PCD}

As the evidence that nitric oxide plays a functional role in the lung increases, research has focused on augmenting levels to observe effects. Most of the work in this field has been undertaken using the NOS substrate L-arginine, which increases FeNO levels in healthy subjects $[81,82,99,100]$.

Nasal nitric oxide and FeNO levels have been compared before and after infusion of intravenous L-arginine in PCD $(n=7)$ and healthy controls $(n=11)$. A 1.4-fold increase in nasal nitric oxide occurred immediately after infusion and a 1.8-fold increase in FeNO $3 \mathrm{~h}$ after infusion in PCD patients. However concentrations remained reduced compared with the baseline values of the control group [82]. Another group compared the use of nebulised L-arginine in 10 PCD patients with 10 healthy controls in a double-blinded, placebo-controlled trial. They found that Larginine not only increased nasal nitric oxide levels but also increased CBF and decreased mucociliary clearance time [89]. However, they did not define the functional or ultrastructural defects in their PCD group and, atypically, seven of the 10 patients reported to have PCD had normal $\mathrm{CBF}$, calling into question their diagnosis. The two PCD patients with the common phenotype of static or extremely slow cilia showed no change in CBF following treatment with L-arginine [89].

Another reason for augmenting nitric oxide is its antibacterial properties [27, 101, 102]. Increasing nasal nitric oxide levels potentially reduces nasopharyngeal carriage of pathogens, thereby reducing the risk of lower respiratory tract infection. There is case in the literature of a healthy volunteer showing that nasal application of NOS inhibitors both reduces nasal NO and leads to sinus infection [96, 103].

Nitric oxide has a role in the dispersal of bacterial biofilms. $P$. aeruginosa is the best characterised bacteria to undergo the genetic adaptations from motile planktonic bacteria to a noncytotoxic, nonmotile, mucoid phenotype caused by overproduction of a surface polysaccharide known as alginate. Biofilm formation also occurs with Haemophilus influenzae and S. aureus, common pathogens in the PCD population [104-106]. Bacteria embedded within biofilms can be 1,000-fold more resistant to antibiotic treatments [107]. They undergo coordinated dispersal events, in which the bacteria convert back to motile planktonic bacteria. Exposing in vitro P. aeruginosa biofilms to sodium nitroprusside, an nitric oxide donor, has been shown to induce biofilm dispersal, making it more susceptible to antimicrobial treatment [29]. Furthermore, recent studies have demonstrated that the slow release of nitric oxide from charged catheters inhibit Escherichia coli biofilm formation and also that sodium nitrite can kill $P$. aeruginosa, S. aureus and B. cepacia $[27,28]$.

While the evidence that augmenting nitric oxide can improve ciliary function in PCD is not compelling, the potential to promote host defence, by direct bactericidal properties and biofilm dispersal, merits further investigation. However, there is a potential risk that increasing nitric oxide levels may lead to increased nitrosative stress in what is already a pro-inflammatory environment.

\section{SUMMARY}

While the association of low nitric oxide concentrations with PCD has been recognised for $>15$ yrs, the underlying mechanisms remain unclear. We have reviewed the data that demonstrate low levels of nasal nitric oxide in PCD to a degree that renders this a useful screening test. The limited studies to date suggest that biosynthesis of the molecule occurs, and there is little to suggest that increased breakdown or metabolism is responsible for the low levels. There is some direct and circumstantial data to suggest the reduced size of the paranasal sinuses caused by aplasia or opacification and the lack of patency of the osteomeatal complex might contribute. However, this is supported mainly by data from patients diagnosed with PCD who had normal levels of nasal nitric oxide and, given that the vast majority of PCD patients have extremely low nitric oxide levels, it does raise questions over the reliability of their diagnosis or the possibility of them having an usual phenotype of PCD. In order to clarify the underlying cause of the low levels of nitric oxide seen, it is essential to establish both whether the airway epithelium in PCD is able to biosynthesis normal levels of nitric oxide and the role played by abnormalities in the anatomy of the paranasal sinuses. 
There has been speculation that nitric oxide augmentation may be beneficial in PCD and other diseases associated with low nitric oxide. It is unlikely that ciliary function will be normalised in common PCD phenotypes, although it has potential for treatment of patients with secondary dyskinesias. More plausible is the suggestion that nitric oxide augmentation will improve treatment of bacterial infections, particularly where biofilms are implicated. A number of small observational and in vitro studies have been conducted, but larger clinical trials are required before this can be considered a therapeutic option. The clinical implications and future directions of nitric oxide in PCD are presented in table 3.

\section{STATEMENT OF INTEREST}

None declared.

\section{ACKNOWLEDGEMENTS}

The Primary Ciliary Dyskinesia Diagnostic Service is commissioned by the Advisory Group for National Specialised Services (AGNSS).

\section{REFERENCES}

1 Chilvers MA, Rutman A, O'Callaghan C. Ciliary beat pattern is associated with specific ultrastructural defects in primary ciliary dyskinesia. J Allergy Clin Immunol 2003; 112: 518-524.

2 Bush A, Cole P, Hariri M, et al. Primary ciliary dyskinesia: diagnosis and standards of care. Eur Respir J 1998; 12: 982-988.

3 Lundberg JO, Weitzberg E, Nordvall SL, et al. Primarily nasal origin of exhaled nitric oxide and absence in Kartagener's syndrome. Eur Respir J 1994; 7: 1501-1504.

4 Morris SM Jr., Billiar TR. New insights into the regulation of inducible nitric oxide synthesis. Am J Physiol 1994; 266: E829-E839.

5 Bush A, Chodhari R, Collins N, et al. Primary ciliary dyskinesia: current state of the art. Arch Dis Child 2007; 92: 1136-1140.

6 Barbato A, Frischer T, Kuehni CE, et al. Primary ciliary dyskinesia: a consensus statement on diagnostic and treatment approaches in children. Eur Respir J 2009; 34: 1264-1276.

7 Karadag B, James AJ, Gultekin E, et al. Nasal and lower airway level of nitric oxide in children with primary ciliary dyskinesia. Eur Respir J 1999; 13: 1402-1405.

8 Narang I, Ersu R, Wilson NM, et al. Nitric oxide in chronic airway inflammation in children: diagnostic use and pathophysiological significance. Thorax 2002; 57: 586-589.

9 Ignarro LJ, Buga GM, Wood KS, et al. Endothelium-derived relaxing factor produced and released from artery and vein is nitric oxide. Proc Natl Acad Sci USA 1987; 84: 9265-9269.

10 Hong H, Sun J, Cai W. Multimodality imaging of nitric oxide and nitric oxide synthases. Free Radic Biol Med 2009; 47: 684-698.

11 Ricciardolo FL. Multiple roles of nitric oxide in the airways. Thorax 2003; 58: 175-182.

12 Liu X, Miller MJ, Joshi MS, et al. Diffusion-limited reaction of free nitric oxide with erythrocytes. J Biol Chem 1998; 273: 18709-18713.

13 Ricciardolo FL, Di Stefano A, Sabatini F, et al. Reactive nitrogen species in the respiratory tract. Eur J Pharmacol 2006; 533: 240-252.

14 Asano K, Chee CB, Gaston B, et al. Constitutive and inducible nitric oxide synthase gene expression, regulation., and activity in human lung epithelial cells. Proc Natl Acad Sci USA 1994; 91: 10089-10093.

15 Kobzik L, Bredt DS, Lowenstein CJ, et al. Nitric oxide synthase in human and rat lung: immunocytochemical and histochemical localization. Am J Respir Cell Mol Biol 1993; 9: 371-377.

16 Pechkovsky DV, Zissel G, Goldmann T, et al. Pattern of NOS2 and NOS3 mRNA expression in human A549 cells and primary cultured AEC II. Am J Physiol Lung Cell Mol Physiol 2002; 282: L684-L692.
17 Warner RL, Paine R III, Christensen PJ, et al. Lung sources and cytokine requirements for in vivo expression of inducible nitric oxide synthase. Am J Respir Cell Mol Biol 1995; 12: 649-661.

18 Lundberg JO, Farkas-Szallasi T, Weitzberg E, et al. High nitric oxide production in human paranasal sinuses. Nat Med 1995; 1 : 370-373.

19 Shaul PW, North AJ, Wu LC, et al. Endothelial nitric oxide synthase is expressed in cultured human bronchiolar epithelium. J Clin Invest 1994; 94: 2231-2236.

20 Sisson JH. Ethanol stimulates apparent nitric oxide-dependent ciliary beat frequency in bovine airway epithelial cells. Am J Physiol 1995; 268: L596-L600.

21 Sisson JH, Pavlik JA, Wyatt TA. Alcohol stimulates ciliary motility of isolated airway axonemes through a nitric oxide, cyclase, and cyclic nucleotide-dependent kinase mechanism. Alcohol Clin Exp Res 2009; 33: 610-616.

22 Alberty J, Stoll W, Rudack C. The effect of endogenous nitric oxide on mechanical ciliostimulation of human nasal mucosa. Clin Exp Allergy 2006; 36: 1254-1259.

23 Wyatt TA, Forget MA, Sisson JH. Ethanol stimulates ciliary beating by dual cyclic nucleotide kinase activation in bovine bronchial epithelial cells. Am J Pathol 2003; 163: 1157-1166.

24 Uzlaner N, Priel Z. Interplay between the NO pathway and elevated $\left[\mathrm{Ca}^{2+}\right]_{\mathrm{i}}$ enhances ciliary activity in rabbit trachea. J Physiol 1999; 516: 179-190.

25 Jain B, Rubinstein I, Robbins RA, et al. TNF- $\alpha$ and IL-1 $\beta$ upregulate nitric oxide-dependent ciliary motility in bovine airway epithelium. Am J Physiol 1995; 268: L911-L917.

26 Jain B, Rubinstein I, Robbins RA, et al. Modulation of airway epithelial cell ciliary beat frequency by nitric oxide. Biochem Biophys Res Commun 1993; 191: 83-88.

27 Major TA, Panmanee W, Mortensen JE, et al. Sodium nitritemediated killing of the major cystic fibrosis pathogens Pseudomonas aeruginosa, Staphylococcus aureus, and Burkholderia cepacia under anaerobic planktonic and biofilm conditions. Antimicrob Agents Chemother 2010; 54: 4671-4677.

28 Regev-Shoshani G, Ko M, Miller C, et al. Slow release of nitric oxide from charged catheters and its effect on biofilm formation by Escherichia coli. Antimicrob Agents Chemother 2010; 54: 273-279.

29 Barraud N, Hassett DJ, Hwang SH, et al. Involvement of nitric oxide in biofilm dispersal of Pseudomonas aeruginosa. J Bacteriol 2006; 188: 7344-7353.

30 Stannard WA, Chilvers MA, Rutman AR, et al. Diagnostic testing of patients suspected of primary ciliary dyskinesia. Am J Respir Crit Care Med 2010; 181: 307-314.

31 Kuehni CE, Frischer T, Strippoli MP, et al. Factors influencing age at diagnosis of primary ciliary dyskinesia in European children. Eur Respir J 2010; 36: 1248-1258.

32 Lucas JSA, Walker WT, Kuehni CE, et al. Primary ciliary dyskinesia. Eur Respir Monogr 2011; 54: 201-217.

33 Narayan D, Krishnan SN, Upender M, et al. Unusual inheritance of primary ciliary dyskinesia (Kartagener's syndrome). J Med Genet 1994; 31: 493-496.

34 Kamiya R. Exploring the function of inner and outer dynein arms with Chlamydomonas mutants. Cell Motil Cytoskeleton 1995; 32: $98-102$.

35 Satir P. Structural basis of ciliary movement. Environ Health Perspect 1980; 35: 77-82.

36 Berg JS, Evans JP, Leigh MW, et al. Next generation massively parallel sequencing of targeted exomes to identify genetic mutations in primary ciliary dyskinesia: implications for application to clinical testing. Genet Med 2011; 13: 218-229.

37 Merveille AC, Davis EE, Becker-Heck A, et al. CCDC39 is required for assembly of inner dynein arms and the dynein regulatory complex and for normal ciliary motility in humans and dogs. Nat Genet 2011; 43: 72-78. 
38 Schwabe GC, Hoffmann K, Loges NT, et al. Primary ciliary dyskinesia associated with normal axoneme ultrastructure is caused by DNAH11 mutations. Hum Mutat 2008; 29: 289-298.

39 Bartoloni L, Blouin JL, Pan Y, et al. Mutations in the DNAH11 (axonemal heavy chain dynein type 11) gene cause one form of situs inversus totalis and most likely primary ciliary dyskinesia. Proc Natl Acad Sci USA 2002; 99: 10282-10286.

40 Lucas JS, Adam EC, Goggin PM, et al. Static respiratory cilia associated with mutations in Dnahc11/DNAH11: a mouse model of PCD. Hum Mutat 2012; 33: 495-503.

41 O'Callaghan $C$, Chilvers $M$, Hogg $C$, et al. Diagnosing primary ciliary dyskinesia. Thorax 2007; 62: 656-657.

42 Hirst RA, Rutman A, Williams G, et al. Ciliated air-liquid cultures as an aid to diagnostic testing of primary ciliary dyskinesia. Chest 2010; 138: 1441-1447.

43 Canciani M, Barlocco EG, Mastella G, et al. The saccharin method for testing mucociliary function in patients suspected of having primary ciliary dyskinesia. Pediatr Pulmonol 1988; 5: 210-214.

44 Gustafsson LE, Leone AM, Persson MG, et al. Endogenous nitric oxide is present in the exhaled air of rabbits, guinea pigs and humans. Biochem Biophys Res Commun 1991; 181: 852-857.

45 Lundberg JO, Rinder J, Weitzberg E, et al. Nasally exhaled nitric oxide in humans originates mainly in the paranasal sinuses. Acta Physiol Scand 1994; 152: 431-432.

46 Lundberg JO, Weitzberg E, Rinder J, et al. Calcium-independent and steroid-resistant nitric oxide synthase activity in human paranasal sinus mucosa. Eur Respir J 1996; 9: 1344-1347.

47 Horvath I, Loukides S, Wodehouse T, et al. Comparison of exhaled and nasal nitric oxide and exhaled carbon monoxide levels in bronchiectatic patients with and without primary ciliary dyskinesia. Thorax 2003; 58: 68-72.

48 Corbelli R, Bringolf-Isler B, Amacher A, et al. Nasal nitric oxide measurements to screen children for primary ciliary dyskinesia. Chest 2004; 126: 1054-1059.

49 Paraskakis E, Zihlif N, Bush A. Nitric oxide production in PCD: possible evidence for differential nitric oxide synthase function. Pediatr Pulmonol 2007; 42: 876-880.

50 Csoma Z, Bush A, Wilson NM, et al. Nitric oxide metabolites are not reduced in exhaled breath condensate of patients with primary ciliary dyskinesia. Chest 2003; 124: 633-638.

51 Shoemark A, Wilson R. Bronchial and peripheral airway nitric oxide in primary ciliary dyskinesia and bronchiectasis. Respir Med 2009; 103: 700-706.

52 Wodehouse T, Kharitonov SA, Mackay IS, et al. Nasal nitric oxide measurements for the screening of primary ciliary dyskinesia. Eur Respir J 2003; 21: 43-47.

53 Marthin JK, Nielsen KG. Choice of nasal nitric oxide technique as first line test for primary ciliary dyskinesia. Eur Respir J 2011; 37: 559-565.

54 Pifferi M, Caramella D, Cangiotti AM, et al. Nasal nitric oxide in atypical primary ciliary dyskinesia. Chest 2007; 131: 870-873.

55 Montella S, Alving K, Maniscalco M, et al. Measurement of nasal nitric oxide by hand-held and stationary devices. Eur J Clin Invest 2011; 41: 1063-1070.

56 American Thoracic Society, European Respiratory Society. ATS/ ERS recommendations for standardized procedures for the online and offline measurement of exhaled lower respiratory nitric oxide and nasal nitric oxide, 2005. Am J Respir Crit Care Med 2005; 171: 912-930.

57 Piacentini GL, Bodini A, Peroni D, et al. Nasal nitric oxide for early diagnosis of primary ciliary dyskinesia: practical issues in children. Respir Med 2008; 102: 541-547.

58 Pifferi M, Bush A, Caramella D, et al. Agenesis of paranasal sinuses and nasal nitric oxide in primary ciliary dyskinesia. Eur Respir J 2011; 37: 566-571.

59 Balfour-Lynn IM, Laverty A, Dinwiddie R. Reduced upper airway nitric oxide in cystic fibrosis. Arch Dis Child 1996; 75: 319-322.
60 Nakano $\mathrm{H}$, Ide $\mathrm{H}$, Imada $\mathrm{M}$, et al. Reduced nasal nitric oxide in diffuse panbronchiolitis. Am J Respir Crit Care Med 2000; 162: 2218-2220.

61 Colantonio D, Brouillette L, Parikh A, et al. Paradoxical low nasal nitric oxide in nasal polyposis. Clin Exp Allergy 2002; 32: 698-701.

62 Lindberg S, Cervin A, Runer T. Nitric oxide (NO) production in the upper airways is decreased in chronic sinusitis. Acta Otolaryngol 1997; 117: 113-117.

63 Kharitonov SA, Robbins RA, Yates D, et al. Acute and chronic effects of cigarette smoking on exhaled nitric oxide. Am J Respir Crit Care Med 1995; 152: 609-612.

64 George SC, Hogman M, Permutt S, et al. Modeling pulmonary nitric oxide exchange. J Appl Physiol 2004; 96: 831-839.

65 Tsoukias NM, George SC. A two-compartment model of pulmonary nitric oxide exchange dynamics. J Appl Physiol 1998; 85: 653-666.

66 Mahut B, Escudier E, de Blic J, et al. Impairment of nitric oxide output of conducting airways in primary ciliary dyskinesia. Pediatr Pulmonol 2006; 41: 158-163.

67 Grasemann H, Tomkiewicz R, Ioannidis I, et al. Metabolites of nitric oxide and viscoelastic properties of airway secretions in cystic fibrosis. Am J Respir Crit Care Med 1997; 155: 46.

68 Elphick HE, Demoncheaux EA, Ritson S, et al. Exhaled nitric oxide is reduced in infants with cystic fibrosis. Thorax 2001; 56: 151-152.

69 Grasemann H, Schwiertz R, Matthiesen S, et al. Increased arginase activity in cystic fibrosis airways. Am J Respir Crit Care Med 2005; 172: 1523-1528.

70 Gaston B, Ratjen F, Vaughan JW, et al. Nitrogen redox balance in the cystic fibrosis airway: effects of antipseudomonal therapy. Am J Respir Crit Care Med 2002; 165: 387-390.

71 Santamaria F, De Stefano S, Montella S, et al. Nasal nitric oxide assessment in primary ciliary dyskinesia using aspiration, exhalation, and humming. Med Sci Monit 2008; 14: CR80-CR85.

72 Radi R, Beckman JS, Bush KM, et al. Peroxynitrite-induced membrane lipid peroxidation: the cytotoxic potential of superoxide and nitric oxide. Arch Biochem Biophys 1991; 288: 481-487.

73 Jones KL, Bryan TW, Jinkins PA, et al. Superoxide released from neutrophils causes a reduction in nitric oxide gas. Am I Physiol 1998; 275: L1120-L1126.

74 Gaston B, Singel D, Doctor A, et al. S-nitrosothiol signaling in respiratory biology. Am J Respir Crit Care Med 2006; 173: 1186-1193.

75 Thomas DD, Ridnour LA, Isenberg JS, et al. The chemical biology of nitric oxide: implications in cellular signaling. Free Radic Biol Med 2008; 45: 18-31.

76 Brett SJ, Evans TW. Measurement of endogenous nitric oxide in the lungs of patients with the acute respiratory distress syndrome. Am J Respir Crit Care Med 1998; 157: 993-997.

77 Zihlif N, Paraskakis E, Tripoli C, et al. Markers of airway inflammation in primary ciliary dyskinesia studied using exhaled breath condensate. Pediatr Pulmonol 2006; 41: 509-514.

78 Bush A, Payne D, Pike S, et al. Mucus properties in children with primary ciliary dyskinesia: comparison with cystic fibrosis. Chest 2006; 129: 118-123.

79 Kelley TJ, Drumm ML. Inducible nitric oxide synthase expression is reduced in cystic fibrosis murine and human airway epithelial cells. J Clin Invest 1998; 102: 1200-1207.

80 Grasemann H, Schwiertz R, Grasemann C, et al. Decreased systemic bioavailability of L-arginine in patients with cystic fibrosis. Respir Res 2006; 7: 87.

81 Grasemann H, Kurtz F, Ratjen F. Inhaled L-arginine improves exhaled nitric oxide and pulmonary function in patients with cystic fibrosis. Am J Respir Crit Care Med 2006; 174: 208-212.

82 Grasemann H, Gartig SS, Wiesemann HG, et al. Effect of Larginine infusion on airway NO in cystic fibrosis and primary ciliary dyskinesia syndrome. Eur Respir J 1999; 13: 114-118. 
83 Lane C, Knight D, Burgess S, et al. Epithelial inducible nitric oxide synthase activity is the major determinant of nitric oxide concentration in exhaled breath. Thorax 2004; 59: 757-760.

84 Meng QH, Springall DR, Bishop AE, et al. Lack of inducible nitric oxide synthase in bronchial epithelium: a possible mechanism of susceptibility to infection in cystic fibrosis. J Pathol 1998; 184: 323-331.

85 Moeller A, Horak F Jr., Lane C, et al. Inducible NO synthase expression is low in airway epithelium from young children with cystic fibrosis. Thorax 2006; 61: 514-520.

86 Gucuyener K, Ergenekon E, Erbas D, et al. The serum nitric oxide levels in patients with Duchenne muscular dystrophy. Brain Dev 2000; 22: 181-183.

87 Niebroj-Dobosz I, Hausmanowa-Petrusewicz I. The involvement of oxidative stress in determining the severity and progress of pathological processes in dystrophin-deficient muscles. Acta Biochim Pol 2005; 52: 449-452.

88 Grozdanovic Z, Christova T, Gosztonyi G, et al. Absence of nitric oxide synthase I despite the presence of the dystrophin complex in human striated muscle. Histochem J 1997; 29: 97-104.

89 Loukides S, Kharitonov S, Wodehouse T, et al. Effect of arginine on mucociliary function in primary ciliary dyskinesia. Lancet 1998; 352: 371-372.

90 Weitzberg E, Lundberg JO. Humming greatly increases nasal nitric oxide. Am J Respir Crit Care Med 2002; 166: 144-145.

91 Lundberg JO, Maniscalco M, Sofia M, et al. Humming, nitric oxide, and paranasal sinus obstruction. JAMA 2003; 289: 302-303.

92 Lundberg JO. Nitric oxide and the paranasal sinuses. Anat Rec (Hoboken) 2008; 291: 1479-1484.

93 Maniscalco M, Weitzberg E, Sundberg J, et al. Assessment of nasal and sinus nitric oxide output using single-breath humming exhalations. Eur Respir J 2003; 22: 323-329.

94 Paulsson B, Dolata J, Larsson I, et al. Paranasal sinus ventilation in healthy subjects and in patients with sinus disease evaluated with the 133-xenon washout technique. Ann Otol Rhinol Laryngol 2001; 110: 667-674.

95 Struben VM, Sewbalak WV, Wieringa $\mathrm{MH}$, et al. Nasal nitric oxide in cystic fibrosis with and without humming. Eur J Clin Invest 2007; 37: 140-144.
96 Deja M, Busch T, Bachmann S, et al. Reduced nitric oxide in sinus epithelium of patients with radiologic maxillary sinusitis and sepsis. Am J Respir Crit Care Med 2003; 168: 281-286.

97 Gomez R, Perez Trullen A, Ruiz C, et al. Discinesia ciliar primaria con agenesia del seno frontal [Primary ciliary dyskinesia with frontal sinus agenesis]. Acta Otorrinolaringol Esp 1997; 48: 315-316.

98 Nishioka GJ, Cook PR, McKinsey JP, et al. Paranasal sinus computed tomography scan findings in patients with cystic fibrosis. Otolaryngol Head Neck Surg 1996; 114: 394-399.

99 Kharitonov SA, Lubec G, Lubec B, et al. L-arginine increases exhaled nitric oxide in normal human subjects. Clin Sci (Lond) 1995; 88: 135-139.

100 Ratjen F, Gartig S, Wiesemann HG, et al. Effect of inhaled nitric oxide on pulmonary function in cystic fibrosis. Respir Med 1999; 93: 579-583.

101 MacMicking JD, Nathan C, Hom G, et al. Altered responses to bacterial infection and endotoxic shock in mice lacking inducible nitric oxide synthase. Cell 1995; 81: 641-650.

102 Wei XQ, Charles IG, Smith A, et al. Altered immune responses in mice lacking inducible nitric oxide synthase. Nature 1995; 375: 408-411.

103 Lundberg JO. Acute purulent sinusitis triggered by topical nasal nitric oxide synthase inhibition. Am J Respir Crit Care Med 2005; 172: 512-513.

104 Arce FT, Carlson R, Monds J, et al. Nanoscale structural and mechanical properties of nontypeable Haemophilus influenzae biofilms. J Bacteriol 2009; 191: 2512-2520.

105 Stoodley P, Nistico L, Johnson S, et al. Direct demonstration of viable Staphylococcus aureus biofilms in an infected total joint arthroplasty. A case report. J Bone Joint Surg Am 2008; 90: 1751-1758.

106 Noone PG, Leigh MW, Sannuti A, et al. Primary ciliary dyskinesia: diagnostic and phenotypic features. Am J Respir Crit Care Med 2004; 169: 459-467.

107 Brooun A, Liu S, Lewis K. A dose-response study of antibiotic resistance in Pseudomonas aeruginosa biofilms. Antimicrob Agents Chemother 2000; 44: 640-646. 